\title{
The Enduring Killer Pole Position of Cardiovascular Diseases in Women
}

Jean-Pierre Usdin*

Ex-Chief and Co-Founder of the American Hospital of Paris Cardiologic Department, France

\section{Introduction}

Towards the end of 90s marvellous campaigns promote the burden of cardiovascular diseases in women. The goal was to alarm public, and physicians, about the damages of heart diseases in women, leading cause of death at the side of cancers.

Towards the end of 90s women were not aware of the tribute they pay to cardiovascular death and so are the physicians. Cancer, especially breast cancer, was the main purpose of women's fear.

Go Red for Women in US, Women at Heart campaigns in Europe, were specially committed. The American Heart Association took important part in this crusade: a pictured expressive cover page (so unusual for the publishers!), special focuses were published in one issue of emblematic "Circulation" [1]. Very similar to Cancer campaigns, Radio, TV announcements, Press publications were launched.

For sure cardiovascular diseases and cancer have similarities: Both are chronic, long lasting, devastating: the label 3FOUR 50 [2] outlines their comparable modifiable behaviours, their worldwide diffusion, and threat.

\section{So What?}

Twenty years after the situation did not change as wanted: cardiovascular diseases are still the first women's cause of death far before all kind of cancers. Cardiovascular diseases are not women's and physicians' top concern [3].

\section{What Happened?}

There are women, medical, physiologic, and institutional reasons.

\section{Women}

\section{Cardiac disease, not so serious!}

In people mind, and especially women, the fear of suffering from a cancer is extremely more important than having a cardiac event. Women continue to believe female hormones protect them against atheroma. Atypical chest pains in a 40/50 year-old woman, hot flashes, short breath still do not raise a vascular suspicion. If you add this: except for sudden death or incapacitating stroke, a vascular problem appears, sure as an acute, but a brief episode in life, easy to deal, and why not: an eventuality! You have the ingredients of an ephemeral experience. Cholesterol levels or whatever cardiac markers are not analysed as Ca $125 \ldots$... cardiac supervision is rare in a woman life.

\section{Adherence to the treatment!}

Cardiac therapy is long lasting, furthermore during follow up pills are added to the previous ones. Adherence to treatment is a real problem. Any side effect (minimal if we compare with oncology) seems sufficient to decrease or stop the treatment. Inexpensive, life-saving aspirin is omitted by $50 \%$ of patients with a history of acute coronary syndrome. Recently researchers of HeartStrong randomized trial demonstrate that financial invectives were not sufficient to obtain a significant adherence [4]

\section{Modifiable dreadful behaviours!}

Women continue to pay heavy price to smoking habit, poor exercise, overweight [5]. Socio economics problems, education, women's role in certain communities, ethnicity, can also play an important role. Black women suffer more than black men and more than white women from fatal and non-fatal ischemic cardiac event [6].

Socio economic problem or not, an alarming number of young women suffer from heart attack. Harmful parents' behaviours unfortunately spread to their children. Young do not seem aware of the effects of poor diet, tobacco. Telling to an adolescent girl or young woman the cardiovascular risk of such a way of life have only minimal success, some are eventually too afraid to talk about [3].

\section{Screening routine!}

Women accept regular echography, mammography, and gynaecologist consultations, but rarely come for a cardiac evaluation, being in a high risk group or not. More! Women prefer to postpone their appointment with their physician after having lost weight, and consider overweight and cancer more serious than cardiovascular diseases! [3].

\section{Physicians}

\section{Atypical ischemic symptoms and insufficient medical preparation}

New doctors' generation are instructed about the multiple atypical symptoms reported by women, but most of the physicians left university twenty (or more) years ago. Most of us, remain with the male typical myocardial: "squeezing, central chest heaviness with radiation..." symptoms, very far from women real ischemic event description: "short breath, sharp pain, palpitations, fatigue, right arm numbness, brief or long warning sign,". On the same idea Transient Ischemic Attack may mimic a migraine aura, so precious time is wasted. Twenty two per cent of physicians and less than $50 \%$ cardiologists felt prepared to assess women cardiovascular disease and used Cardiac Society Recommendations [3]

\section{Past history}

Complications of pregnancies such as High Blood Pressure, preeclampsia, eclampsia and diabetes, are not always recognized as

*Corresponding author:Jean-Pierre Usdin, Ex-Chief and Co-Founder of the American Hospital of Paris Cardiologic Department, France, Tel: 0033684283073 E-mail: jp.usdin@cabinet-desperey.fr

Received August 16, 2017; Accepted August 25, 2017; Published August 29 2017

Citation: Usdin JP (2017) The Enduring Killer Pole Position of Cardiovascular Diseases in Women. J Vasc Med Surg 5: 331. doi: 10.4172/2329-6925.1000331

Copyright: (c) 2017 Usdin JP. This is an open-access article distributed under the terms of the Creative Commons Attribution License, which permits unrestricted use, distribution, and reproduction in any medium, provided the original author and source are credited. 
vascular risk factors. These past events are rarely disclosed by women in consultation, more than 20 years after. Physicians have to search in medical history the possibility of a vascular problem during the pregnancies. Investigations therefore, are crucial due to the future high cardiovascular risk they imply [7].

\section{Physiology and Anatomy}

\section{Vascular beds, endothelial function}

Heart physiology, in female and male, appears to be different [8]. Myocardial infarction with normal coronary arteries in women is well established, coronary artery spasm is more likely to happen in women than in men. Endothelial (dys) function is a part of many researches.

Vascular and haemorrhagic complications during or following a coronary angiogram are more frequent in women. Peripheral arteries are thinner and radial approach may be difficult as brachial artery is prone to vasoconstriction.

It is not infrequent to find small coronary arteries not accessible to angioplasty or revascularization. Small cardiac vessels' disease is not rare and treatment sometimes empiric.

These differences may lead some physicians (and cardiologists) to the unacceptable decision to perform less invasive approach in women.

\section{Government and Medical Societies}

\section{Behaviours and publicity}

Politics: they took important and difficult decisions concerning tobacco notably in US cities as smoking ban in every part of many metropoles. Increasing the price of cigarettes, neutral packs unfortunately are not sufficient: it remains about $16 \%$ of smokers in occidental countries, mostly women (young ones).

Labels concerning the levels of calories, fat content, and category of fat are wide spread but the way to have a healthy diet begins at school and continues at home. Campaigns are on the way, long term effects are expected to be soon noticeable [9].

\section{Government}

Financial aids are wanted in the direction of cardiovascular disease in women: attribution is less than $50 \%$ of credits allocate to female cancers surveys [3].

\section{Medical societies}

They have also a role to play, by informing, and introducing to large public the benefits of healthy comportments, but not only. They definitely have to demonstrate a strong attitude, and robust acts against cholesterol detractors! For example: denouncing firmly to public, the flawed, fractional information about cholesterol treatment, so disastrous for secondary prevention. No more blood component is more decried than cholesterol. Subjective data rail against statin and cholesterol treatments by some scientists or physicians (who never had known what a patient is or, who left the clinician field). Unfortunately they find a generous hearing in media, and knock down the beneficial and recognized effect of lowering cholesterol in specific population.

\section{What's Now?}

Twenty years were not enough to bring cardiovascular disease awareness to women and physicians as a daily concern, in spite of excellent campaigns. Regular public information, Financial aids from government, dedicated sessions during congress (no one is scheduled during next congress of European Society of Cardiology!) Frank dialogue , to be also delivered to daughters, family and friends during physician's consultations, regular check of blood pressure, weight, encouragement to physical activity, recommendations to quit tobacco are still the gold standard.

The take home message to women is: The fight against tobacco, obesity, poor exercise has at least a double beneficial effect: deliver of cardiovascular and cancer burden. We should have that dream: place the cardiovascular diseases in the pole position of eradication!

\section{References}

1. Merz NB, Bonow RO, Sopko G, Balaban RS, Cannon RO, et al. (2004) Women‘s Ischemic Syndrome Evaluation. AHA/ NHLBI Conferences Proceedings. Circulation 109: 805-807.

2. Visagie C (2009) Health 24. Heart Health.

3. Bairey Merz CN, Andersen H, Sprague E, Burns A, Keida M, et al. (2017) Knowledge, Attitudes, and Beliefs Regarding Cardiovascular Disease in Women: The Women's Heart Alliance. J Am Coll Cardiol 70: 123-132.

4. Volpp KG, Troxel AB, Mehta SJ, Norton L, Zhu J, et al. (2017) Effect of Electronic Reminders, Financial Incentives, and Social Support on Outcomes After Myocardial Infarction: The HeartStrong Randomized Clinical Trial. JAMA Intern Med 177: 1093-1101.

5. The GDB 2015 Obesity Collaborators (2017) Health effects of Overweight and Obesity in 195 Countries over 25 years. N Engl J Med 377: 13-27.

6. Colantonio LD, Gamboa CM, Richman JS, Levitan EB, Soliman EZ, et al. (2017) Black-White differences in incident fatal, non-fatal and total coronary heart disease. Circulation 136: 152-166.

7. Timpka S, Stuart JJ, Tanz LJ, Rimm EB, Franks PW, et al. (2017) Lifestyle in Progression from Hypertensive Disorders of Pregnancy to Chronic Hypertension in Nurses' Health Study II: Observational Cohort Study. BMJ 358: j3024.

8. Badinon L, Bugiardini R, Cenko E, Cubedo J, Dorobantu M, et al. (2017) Coronary pathophysiology and microcirculation. Eur Heart J 38: 1951.

9. MSNBC News (2014) Sesame Street's new makeover includes new "D Ruster". 